\title{
Pulmonary Rehabilitation in Patients with Chronic Obstructive Pulmonary Disease and Metabolic Syndrome
}

\author{
Andrey V. Budnevsky, PhD, ScD; Svetlana A. Kozhevnikova, PhD; \\ Evgeniy S. Ovsyannikov, PhD*; Alexey V. Chernov, PhD, ScD \\ Voronezh State Medical University named after N.N. Burdenko \\ Voronezh, the Russian Federation
}

\begin{abstract}
Background: Chronic obstructive pulmonary disease (COPD) is widespread and often combined with other diseases, including metabolic syndrome (MS), which are closely related. The purpose of this study was to assess the clinical efficacy of a pulmonary rehabilitation (PR) program for patients with COPD and MS, in addition to standard therapy.

Materials and Methods: We examined 70 patients with COPD and MS. The patients were divided into 2 groups. Group I included 35 patients who received standard pharmacologic therapy in combination with PR. Group II included 35 patients who received only standard pharmacologic therapy.

Results: Group I patients demonstrated a decrease in exacerbation events from $3.96 \pm 0.43$ to $2.24 \pm 0.10(P=0.0002)$, in emergency service calls from $3.80 \pm 0.37$ to $1.59 \pm 0.25(P=0.0000)$, and in hospital admissions from $2.93 \pm 0.11$ to $1.41 \pm 0.24$ $(P=0.0004)$ per year, as well as a significant decrease in the severity of COLD symptoms, improvements in exercise tolerance, MS components and QL physical and psychological domains, compared to Group II.

Conclusion: The main benefits of a comprehensive PR program for patients with COPD and MS include a decrease in symptoms (dyspnea and fatigue), improvements in exercise tolerance, and reduction in health care utilization (particularly beddays), as well as an increase in physical activity and an improvement in MS components. (International Journal of Biomedicine. 2017;7(3):171-174.)
\end{abstract}

Key Words: chronic obstructive pulmonary disease $\bullet$ metabolic syndrome $\bullet$ pulmonary rehabilitation $\bullet$ quality of life

\section{Abbreviations}

6MWT, the 6-minute walk test; COPD, chronic obstructive pulmonary disease; CAT, the COPD assessment test; DBP, diastolic blood pressure; FPG, fasting plasma glucose; HDL-C, high-density lipoprotein cholesterol; LDL-C, low-density lipoprotein cholesterol; OGTT, oral glucose tolerance test; PR, pulmonary rehabilitation; QL, the quality of life; SBP, systolic blood pressure; SGRQ, St. George's Respiratory Questionnaire; SF-6, the Short-Form Health Survey; TG, triglycerides.

\section{Introduction}

COPD belongs to the group of chronic inflammatory lung diseases group that are characterized by incomplete obstruction of reversible airways. It is supposed that COPD will become one of the leading causes of death in the world

*Corresponding author: Evgeniy S. Ovsyannikov, PhD. Department of faculty therapy, Voronezh State Medical University named after N.N. Burdenko. Voronezh, Russia. E-mail: ovses@ yandex.ru. by 2020 , and the high social importance of this disease has been confirmed. ${ }^{(1,2)}$ In patients 40 years of age and more, COPD is often combined with pathology of other organs and systems ${ }^{(2-4)}$ On the other hand, MS affects $20 \%$ to $25 \%$ of the adult population and prevalence is on the increase, owing to obesity and a sedentary lifestyle, affecting as many as $42 \%$ of individuals aged over 60 years. ${ }^{(5-7)}$

According to Global Strategy For The Diagnosis, Management, And Prevention Of Chronic Obstructive Pulmonary Disease, ${ }^{(1)}$ COPD has substantial manifestations beyond the lungs - the so-called systemic effects, such as 
unintentional weight loss and skeletal muscle dysfunction. The chronic systemic inflammation that is linked to COPD may also initiate or exacerbate comorbid diseases, such as cardiovascular disease, osteoporosis, anemia, MS, type 2 diabetes, lung cancer, and depression, and is one of the key mechanisms underlying these extrapulmonary effects. ${ }^{(2-4,4-13)}$.

It is important that COPD is a disease that can be prevented and treated. ${ }^{(1,2)}$ However, over the last two decades, growing evidence of systemic manifestations in COPD patients and their negative effects on the functioning of these patients has accelerated the development and use of nonpharmacological treatments, such as pulmonary rehabilitation (PR). According to GOLD Guidelines, PR and pharmacological therapy must work closely together for a more successful outcome. ${ }^{(1,14-18)}$ PR is a broad program that helps improve the well-being of patients with COPD; it uses exercise, education, and support to help patients to breathe - and function - at the highest level possible. Thus, in cases of the COPD+MS combination, an integrated approach to treatment and prevention and the development of a PR program are necessary.

The purpose of this study was to assess the clinical efficacy of a PR program for patients with COPD and MS, in addition to standard therapy.

\section{Materials and Methods}

We examined 70 patients aged from 18 to 60 years with COPD and MS. The patients were divided into 2 groups. Group I included 35 patients (12/34.3\% women and 23/65.7\% men; mean age, $47.11 \pm 0.44$ years) who received standard pharmacologic therapy in combination with PR. Group II included 35 patients (10/28.6\% women and $25 / 71.4 \%$ men; mean age, $47.08 \pm 0.22$ years) who received only standard pharmacologic therapy. COPD diagnosis was based on the integral assessment of symptoms, medical history, health status, and spirometry values according to GOLD. MS was diagnosed according to the IDF consensus criteria ${ }^{(5)}$ The study was approved by local ethics committee, and written informed consent was obtained from all participants

A comprehensive clinical examination and laboratory tests included the following procedures:

- Anthopometrical Reference Data: body mass index (BMI) was calculated using Quetelet's formula (in $\mathrm{kg} / \mathrm{cm}^{2}$ ). Waist circumference (WC) was measured using centimetric tape at the navel level on a horizontal line (in $\mathrm{cm}$ )

- Assessment of COPD severity included the number of exacerbations, calls to emergency service, and hospital admissions for the past 12 months.

- Quantity assessment of COPD symptoms (dyspnea, cough, sputum production, general weakness) by the 10-point Visual Analogue Scale (VAS).

- Quality assessment of COPD symptoms by a modified British Medical Research Council (mMRC) questionnaire.

- Assessment of QL by SGRQ, SF-36 and CAT.

- Functional tests: spirometry, 6MWT.

- Assessment of blood pressure by Korotkov's method.

- Assessment of FPG, a 2-hour OGTT, blood levels of TG, HDL-C and LDL-C.

\section{Pulmonary Rehabilitation}

The length of the PR program was 5 weeks: 5 practical classes of $1 \mathrm{~h} 30 \mathrm{~min}$ each for groups of 4-5 people. Topics covered were etiology, pathogenesis, symptoms, management and prevention of COPD and MS. For the smoking patients there was additional information about nicotine dependence and its influence on COPD. All the participants were given books, brochures, information sheets and booklets. The PR program for patients with COPD and MS included:

- Education sessions discussing breathing techniques, disease processes, respiratory medications, oxygen therapy, and exercise techniques

- Exercise reconditioning sessions

- Oxygen dosing (when appropriate)

- Nutrition and healthy lifestyle seminar

- Energy conservation techniques.

The patients' education program was followed by a 4-week exercise training program.

\section{Results and Discussion}

During the observation, Group I demonstrated credible changes in some assessment parameters, while Group II showed no statistically significant changes in those parameters.

In Group I patients, we found a decrease in exacerbation events from $3.96 \pm 0.43$ to $2.24 \pm 0.10(P=0.0002)$, in emergency service calls from $3.80 \pm 0.37$ to $1.59 \pm 0.25(P=0.0000)$, and in hospital admissions from $2.93 \pm 0.11$ to $1.41 \pm 0.24$ ( $P=0.0004)$ per year. There were significant improvements in subjective assessment of COPD symptoms according to the 10-point VAS: dyspnea - from $6.03 \pm 0.81$ to $2.66 \pm 0.29(P=0.0001)$, cough - from $5.87 \pm 0.36$ to $2.04 \pm 0.23$ ( $P=0.0002)$, sputum from $3.81 \pm 0.21$ to $1.06 \pm 0.49(P=0.0008)$, general weakness from $4.55 \pm 0.81$ to $1.88 \pm 0.49(P=0.0003)$. This group indicated significant improvement in dyspnea severity measured by mMRC (from $1.74 \pm 0.56$ to $0.94 \pm 0.64(P=0.0000)$. We found also reliable positive dynamics of CAT results (from $22.54 \pm 4.06$ to $16.32 \pm 3.05(P=0.0000)$. Group I demonstrated an obvious improvement in average values of SGRQ results: Symptoms score - from $77.21 \pm 3.78$ to $70.32 \pm 3.46(P=0.0000)$, Activity score - from $70.32 \pm 2.98$ to $58.62 \pm 5.62(P=0.0002)$, Impacts score - from $60.65 \pm 4.81$ to $53.38 \pm 4.37(P=0.0000)$, and total score - from $67.51 \pm 3.78$ to $59.42 \pm 3.86(P=0.0000)$.

Spirometry results were not significantly different in Groups I and II, but Group I showed significant improvement in the 6MWT result (from $347 \pm 6.1 \mathrm{~m}$ to $402 \pm 7.9 \mathrm{~m} ; P=0.0000$ ).

Patients in this group also demonstrated a reliable improvement in QL physical and psychological domains, according to SF-36 (Table 1).

Group I displayed significant improvement in WC (from $111.04 \pm 2.11 \mathrm{~cm}$ to $102.24 \pm 2.79 \mathrm{~cm}$ in women, $P=0.0394$, and from $100.41 \pm 1.56 \mathrm{~cm}$ to $95.16 \pm 1.62 \mathrm{~cm}$ in men, $P=0.0401$ ) and BMI (from $31.93 \pm 0.25 \mathrm{~kg} / \mathrm{m}^{2}$ to $30.65 \pm 0.44 \mathrm{~kg} / \mathrm{m}^{2}$ for the whole group, $P=0.0311$ ).

Group I demonstrated a reliable decrease in SBP (from $151.63 \pm 0.77 \mathrm{mmHg}$ to $146.26 \pm 1.04 \mathrm{mmHg} ; P=0.0001$ ) and DBP (from $96.14 \pm 0.87 \mathrm{mmHg}$ to $91.12 \pm 0.55 \mathrm{mmHg} ;=0.0067$ ). 
Table 1.

$S F-36$ parameters (mean \pm SEM) in two groups

\begin{tabular}{|c|c|c|c|c|}
\hline \multirow{2}{*}{ Parameters } & \multicolumn{2}{|c|}{ Group I } & \multicolumn{2}{c|}{ Group II } \\
\cline { 2 - 5 } & Baseline & $\begin{array}{c}\text { After 12 } \\
\text { months }\end{array}$ & Baseline & $\begin{array}{c}\text { After 12 } \\
\text { months }\end{array}$ \\
\hline PF & $62.67 \pm 1.02$ & $74.72 \pm 1.93 *$ & $61.53 \pm 1.04$ & $52.35 \pm 1.28$ \\
\hline RP & $41.05 \pm 0.93$ & $53.62 \pm 1.85 *$ & $42.13 \pm 1.27$ & $41.58 \pm 0.92$ \\
\hline BP & $46.35 \pm 1.29$ & $59.22 \pm 2.09 *$ & $45.08 \pm 1.85$ & $46.33 \pm 1.41$ \\
\hline GH & $44.01 \pm 2.12$ & $56.82 \pm 1.69 *$ & $45.82 \pm 2.05$ & $42.72 \pm 1.34$ \\
\hline VT & $54.23 \pm 1.31$ & $65.51 \pm 1.83 *$ & $53.67 \pm 1.03$ & $54.14 \pm 1.22$ \\
\hline SF & $50.32 \pm 1.38$ & $61.23 \pm 1.79 *$ & $49.21 \pm 2.05$ & $47.54 \pm 1.38$ \\
\hline RE & $52.83 \pm 1.88$ & $63.27 \pm 2.19 *$ & $51.36 \pm 1.95$ & $48.78 \pm 1.69$ \\
\hline MH & $61.23 \pm 1.83$ & $73.21 \pm 2.45 *$ & $63.04 \pm 1.59$ & $60.45 \pm 2.01$ \\
\hline
\end{tabular}

PF -Physical Functioning, RP - Role-physical, BP - Bodily Pain, GH -General Health, VT-Vitality, SF - Social Functioning $R E$ - Role-emotional, $M H$-Mental Health; * $P<0.05$.

We did not reveal significant differences in the level of serum lipids, FPG and OGTT between Group I and Group II. However, it should be noted that Group I indicated a tendency to decrease in the levels of TG (from $2.30 \pm 0.24 \mathrm{mmol} / \mathrm{L}$ to $2.20 \pm 0.37 \mathrm{mmol} / \mathrm{L}, \quad P=0.059$ ), LDL-C (from $3.74 \pm 0.82$ $\mathrm{mmol} / \mathrm{L}$ to $3.64 \pm 0.66 \mathrm{mmol} / \mathrm{L}, P=0.053$ ), and to increase in HDL-C level (from $0.86 \pm 0.31 \mathrm{mmol} / \mathrm{L}$ to $0.95 \pm 0.42 \mathrm{mmol} / \mathrm{L}$, $P=0.057$ ), as well as a tendency to decrease in the levels of FPG (from $6.63 \pm 0.46 \mathrm{mmol} / \mathrm{L}$ to $6.25 \pm 0.54 \mathrm{mmol} / \mathrm{L}, P=0.053$ ) and postprandial glucose (from $10.50 \pm 0.74 \mathrm{mmol} / \mathrm{L}$ to $10.01 \pm 0.66$ $\mathrm{mmol} / \mathrm{L}, P=0.058$ ).

Group I demonstrated a significant change of attitude towards smoking: 9(34.6\%) patients out of 26 smokers quit smoking. Patients in this group also demonstrated a reliable improvement in QL physical and psychological domains, according to SF-36.

The main purposes of PR are symptom reduction, reduction in the expense of treatment, recovery of patient functional capacity, and improved QL. The most important aspect of PR is the individual approach, taking into account the degree of respiratory failure manifestation, associated diseases, and systemic COPD symptoms. ${ }^{(19)}$

According to our data, applying a PR program resulted in a significant decrease in the frequencies of COPD exacerbations, emergency service calls, and hospital admissions. In the complex of treatment, PR resulted in a degree of decrease in the manifestation of clinical COPD symptoms, in the severity of dyspnea and its influence on physical activity and patients' health condition, and in the impact of COPD on physical and emotional health and psychosocial adaptation of patients; PR also significantly increased the exercise tolerance and improved QL in the physical and psychological domains. Additionally, a positive influence on MS components was noted, which has added positive effects on the psychoemotional state of patients.

\section{Conclusion}

Thus, a PR program can be considered an important tool for the treatment of patients with COPD and MS. Along with a decrease in the symptoms of the disease, PR promotes respiratory muscle training, training of upper and lower extremity muscle groups, and improvement of the function of the immune system and metabolic processes with positive influence on the cardiovascular system and psychological status. ${ }^{(19)}$ Indeed, the main benefits of a comprehensive PR program for patients with COPD and MS include a decrease in symptoms (dyspnea and fatigue), improvements in exercise tolerance, and reduction in health care utilization (particularly bed-days), as well as an increase in physical activity and an improvement in MS components.

\section{Competing interests}

The authors declare that they have no competing interests.

\section{References}

1. Global Initiative for Chronic Obstructive Lung Disease (GOLD, 2017 REPORT). Available from: http://goldcopd.org/ 2. Budnevskiy AV, Burlachuk VT, Chernov AV, Ovsyannikov ES. Chronic obstructive pulmonary disease. Voronezh: Nauchnaya Kniga; 2014. [in Russian].

3. Malysh EYu, Drobysheva ES, Chernov A.V. [Chronic obstructive pulmonary disease and cardiovascular pathology. Molodoy uchenyy]. 2014;5(64):145-148.[Article in Russian] 4. Budnevskiy AV, Kozhevnikova SA, Kostina NE, Isaeva YaV. Rehabilitation of patients with comorbidity of chronic obstructive pulmonary disease and cardiovascular disease. Voronezh: Nauchnaya Kniga; 2014.[in Russian]

5. IDF Consensus Worldwide Definition of the Metabolic Syndrome, 2006. Available from: https://www.idf.org/elibrary/consensus-statements/60-idfconsensus-worldwidedefinitionof-the-metabolic-syndrome

6. Chazova IE, Nedogoda SV, Zhernakova YuV. Guidelines on management of patients with metabolic syndrome: clinical recommendations of the Healthcare Ministry of Russia Federation. Moscow; 2013. [in Russian].

7. Roytberg GE. Metabolic syndrome. Moscow: MEDpressinform; 2007.[in Russian].

8. Agusti A, Soriano JB. COPD as a systemic disease. COPD. 2008;5(2):133-8. doi: 10.1080/15412550801941349.

9. Barnes PJ, Celli BR. Systemic manifestations and comorbidities of COPD. Eur Respir J. 2009;33(5):1165-1185. doi: 10.1183/09031936.00128008.

10. Fabbri LM, Rabe KF. From COPD to chronic systemic inflammatory syndrome? Lancet. 2007;370(9589):797-9.

11. ZuWallack RL. Functional status and survival in COPD. Monaldi Arch. Chest Dis. 2013;59 (3):230-3.

12. Budnevskiy AV, Ovsyannikov ES, Chernov AV. [Prognostic value of biomarkers for evaluation of treatment efficacy in chronic obstructive pulmonary disease (a review)]. Molodoy Uchenyy. 2014;6 (65):284-287. [Article in Russian].

13. Kireev SA, Ryazanov AS, Eremenko NN, Demenko EG. [Comorbidity of COPD and metabolic syndrome: clinical manifestations and systemic inflammation laboratory parameters]. Biomeditsina. 2010;1(4):40-45. [Article in Russian]. 
14. Stupnitskaya AYa. [Oxidant - antioxidant system in patients with comorbidity of chronic obstructive pulmonary disease and metabolic syndrome]. In: Actual Issues of the Modern Medicine: Proceedings of the 23rd International Applied Science Conference. Novosibirsk: SibAK;2013;9 (23):14-16. [Article in Russian].

15. Budnevskiy AV, Tribuntseva LV, Yakovlev V.N. [Improvement in outpatient care for patients with chronic obstructive pulmonary disease]. Sistemnyy analiz i upravlenie v biomeditsinskikh sistemakh. 2012;11(2):464-468. [Article in Russian].

16. Epifanov VA. Rehabilitation Medicine. Moscow:
GEOTAR Media; 2012. [in Russian].

17. Danyshbaeva AB. [A role of educational and smoking cessation programmes for prevention of chronic obstructive pulmonary disease]. Vestnik Kazakhskogo Natsional'nogo Meditsinskogo Universiteta. 2013;2:24-26. [Article in Russian]. 18. Corhay JL, Dang DN, Van Cauwenberge H, Louis R. Pulmonary rehabilitation and COPD: providing patients a good environment for optimizing therapy. Int J Chron Obstruct Pulmon Dis. 2014;9:27-39. doi: 10.2147/COPD.S52012.

19. Wijkstra PJ, Wempe JB. New tools in pulmonary rehabilitation. Eur Respir J. 2011;38(6):1468-74. doi: 10.1183/09031936.00111911. 